\title{
ACE2 and AT4R are present in diseased human blood vessels
}

\author{
A. Zulli,, ${ }^{1,2}$ L.M. Burrell, ${ }^{1}$ B.F. Buxton, ${ }^{3}$ D.L. Hare ${ }^{1,2}$ \\ ${ }^{1}$ Department of Medicine, University of Melbourne, Austin Health; ${ }^{2}$ Departments of Cardiology and \\ ${ }^{3}$ Cardiac Surgery, Austin Health, Heidelberg, Australia
}

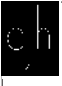

(C)2008 European Journal of Histochemistry

A growing body of evidence suggests that the angiotensin II fragments, Ang(1-7) and Ang(3-8), have a vasoactive role, however ACE2, the enzyme that produces Ang(1-7), or AT4R, the receptor that binds Ang (3-8), have yet been simultaneously localised in both normal and diseased human conduit blood vessels. We sought to determine the immunohistochemical distribution of ACE2 and the AT4R in human internal mammary and radial arteries from patients undergoing coronary artery bypass surgery. We found that ACE2 positive cells were abundant in both normal and diseased vessels, being present in neo-intima and in media. ACE2 positive immunoreactivity was not present in the endothelial layer of the conduit vessels, but was clearly evident in small newly formed angiogenic vessels as well as the vaso vasorum. Endothelial AT4R immunoreactivity were rarely observed in either normal and diseased arteries, but AT4R positive cells were observed adjacent to the internal elastic lamine in the internal mammary artery, in the neo-intima of radial arteries, as well as in the media of both internal mammary artery and radial artery. AT4R was abundant in vaso vasorum and within small angiogenic vessels. Both AT4R and ACE2 colocalised with smooth muscle cell $\alpha$ actin. This study identifies smooth muscle cell $\alpha$ actin positive ACE2 and AT4R in human blood vessels as well as in angiogenic vessels, indicating a possible role for these enzymes in pathological disease.

Key words: human blood vessels, AT4 receptors, ACE2, IRAP.

Correspondence: Anthony Zulli,

Vascular Laboratory, Department of Cardiology, Austin Health, Heidelberg 3084, Australia

Tel.: +61.3.9496.3585.

Fax: +61.3.9457.5485

E-mail: azulli@unimelb.edu.au

Paper accepted on October 31, 2007

European Journal of Histochemistry 2008; vol. 52 issue 1 (Jan-Mar): 39-44 growing body of evidence is emerging to
suggest that the angiotensin II fragments,
angiotensin (1-7) (Ang(1-7)) and angiotensin (3-8) (Ang(3-8)), have vasoactive roles. Ang (1-7), has opposing effects to angiotensin II (Ang II)(Ferrario et al. 1997). For example, Ang (1-7) reduces blood pressure of hypertensive dogs (Nakamoto et al. 1995) and rats (Benter et al. 1995), causes vasodilation (Brosnihan et al. 1996; Porsti et al. 1994), inhibits AngII mediated vasoconstriction (Roks et al. 1999), and inhibits vascular smooth muscle cell growth (Freeman et al. 1996). Recently, a novel enzyme, angiotensin converting enzyme 2 (ACE2), has been identified that converts AngII to Ang (1-7) (Donoghue et al. 2000). ACE2 is increased in cardiovascular disease (Burrell et al. 2005; Paizis et al. 2005) and in rabbit atherosclerotic plaques (Zulli et al. 2006a), while it is decreased in renal disease (Tikellis et al. 2003) indicating a possible role for Ang (1-7) in these tissues.

There is very little information in the literature regarding the cardiovascular effects of the hexapeptide Ang (3-8). Also known as Ang IV, it is a metabolic product of Ang II. ANG II is enzymatically cleaved by aminopeptidase A to form Ang III, which is further cleaved by aminopeptidase M to form Ang IV (Carey and Siragy 2003). Ang IV can act as both a vasodilator and promoter of cell proliferation. Ang IV stimulates vasodilation in the pulmonary arteries (Patel et al. 1998), pial arterioles (Haberl et al. 1991) and increases blood flow in the rat cerebral (Wright et al. 1995) and renal arteries (Swanson et al. 1992). On the other hand, Ang IV stimulates rabbit cardiac fibroblast proliferation (Wang et al. 1995). Ang IV binds specifically to the AT4R, now identified as IRAP (insulin regulated amino peptidase) (Albiston et al. 2001). AT4R have been identified in endothelial cells (Hall et al. 1995), smooth muscle cells 
(Hall et al. 1993) and in rabbit endothelial, medial and neointima of carotid arteries (Moeller et al. 1999).

ACE2 and AT4R have never been demonstrated in the human conduit vessels. Thus in this study, we sought to determine the immunolocalization of both proteins in diseased (radial arteries) and non diseased (internal mammary arteries) human blood vessels.

\section{Materials and Methods}

Segments of human blood vessels ( $n=5$ radial and $n=5$ internal mammary arteries) were obtained from patients undergoing coronary artery bypass grafting. Patients with a mean age of 64 years gave informed consent and all were receiving $H M G$ CoA reductase inhibitors and antihypertensive treatment (ACE inhibitors or diuretics or beta adreno-receptor blockers). Only nontraumatized vessel segment were used in this study. This study was approved by the Austin Hospital Medical Research Ethics Committee and followed institutional guidelines. Harvesting was performed using techniques previously established in our operating theatres (Ruengsakulrach et al. 1999). All vessels were fixed in formalin and were then processed and embedded in a single paraffin blocks as previously described (Zulli et al. 2006b).

\section{Immunohistochemistry}

Sections were randomly selected, dewaxed, rehydrated and placed in $10 \mathrm{mM}$ TrisCl, $\mathrm{pH}$ 7.4. Sections were then preincubated with $1 \%$ goat serum in $10 \mathrm{mM}$ TrisCl ( $\mathrm{pH} 7.4$ ) for twenty minutes before incubating with the primary antibody diluted in $1 \%$ goat serum in $10 \mathrm{mM}$ TrisCl

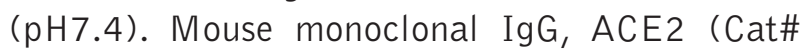
ALX 804-715, Alexis Biochemicals, diluted 1:150), rabbit polyclonal IgG, AT4R (Cat \# IRAP11-A, Alpha Diagnostic, Texas, diluted $1: 100)$, smooth muscle cell $\alpha$ actin monoclonal antibody (Cat \#M0851, Dakocytomation, diluted 1:100) and mouse monoclonal IgG against bacterial glucose oxidase (Cat \# X0931, Dakocytomation, USA, diluted 1:50) and rabbit polyconal IgG (Cat\# X0936, Dakocytomation, diluted 1:50) were used as negative controls. All antibodies were incubated overnight. Immunohistochemistry for both monoclonal and rabbit polyclonal were performed using the Envision commercially available kit following the manufacturers directions (Zulli et al. 2005; Zulli et al. 2006b; Zulli et al. 2007). All antigenic sites were developed with $D A B$, counterstained with hematoxylin, dehydrated and mounted with DPX mounting media.

\section{Results}

ACE2 immunoreactivity was present throughout the vessel wall in all blood vessel types, albeit at differing intensities (Figure 1 F-J). Interestingly, ACE2 immunoreactivity was not observed in the endothelial layer of internal mammary arteries or radial arteries, but was clearly present in the medial layer of these vessels, especially apparent in the radial artery media $(\mathrm{I}, \mathrm{J}$ ) and rarely abundant in the IMA media (G). As well, ACE2 positive cells were present within the neo-intima of radial arteries $(D, E)$. These cells co-localised with smooth muscle cell $\alpha$ actin present just beneath the internal elastic lamina $(K, L)$. ACE2 was also clearly visible in both arterioles and venules of the vaso vasorum (venuels shown, $\mathrm{M}$ ) and single positive cells in the adventitia were commonly observed (arrow, M). Negative control sections show no immunoreactivity $(\mathrm{N}, 0)$.

AT4R immunoreactivity followed a similar pattern of staining to ACE2, being present throughout the vessel wall in all blood vessel types (Figure $2 F-J$ ). Like ACE2, AT4R immunoreactivity was not observed in the endothelial layer of internal mammary arteries or radial arteries, but was clearly present in the medial layer of these vessels, especially apparent in the radial artery media (I, J). As well, AT4R positive cells were present within the neo-intima of radial arteries $(D, E)$. These cells co-localised with smooth muscle cell $\alpha$ actin present in the radial arteries $(N, 0)$. AT4R was also clearly visible in both arterioles (top of $L$ ) and venules (bottom of $L$ ) of the vaso vasorum. Endothelial AT4R immunoreativity was observed in the arteriole $(L)$, but the majority of the staining was observed in the media of the vessels, and correlated with smooth muscle cell $\alpha$ actin (M). Negative control sections to the polyclonal antibody shows no immunoreactivity (IMA shown in $\mathrm{H}, \mathrm{C}$ ).

In the fully occluded radial artery (Figure 3), 


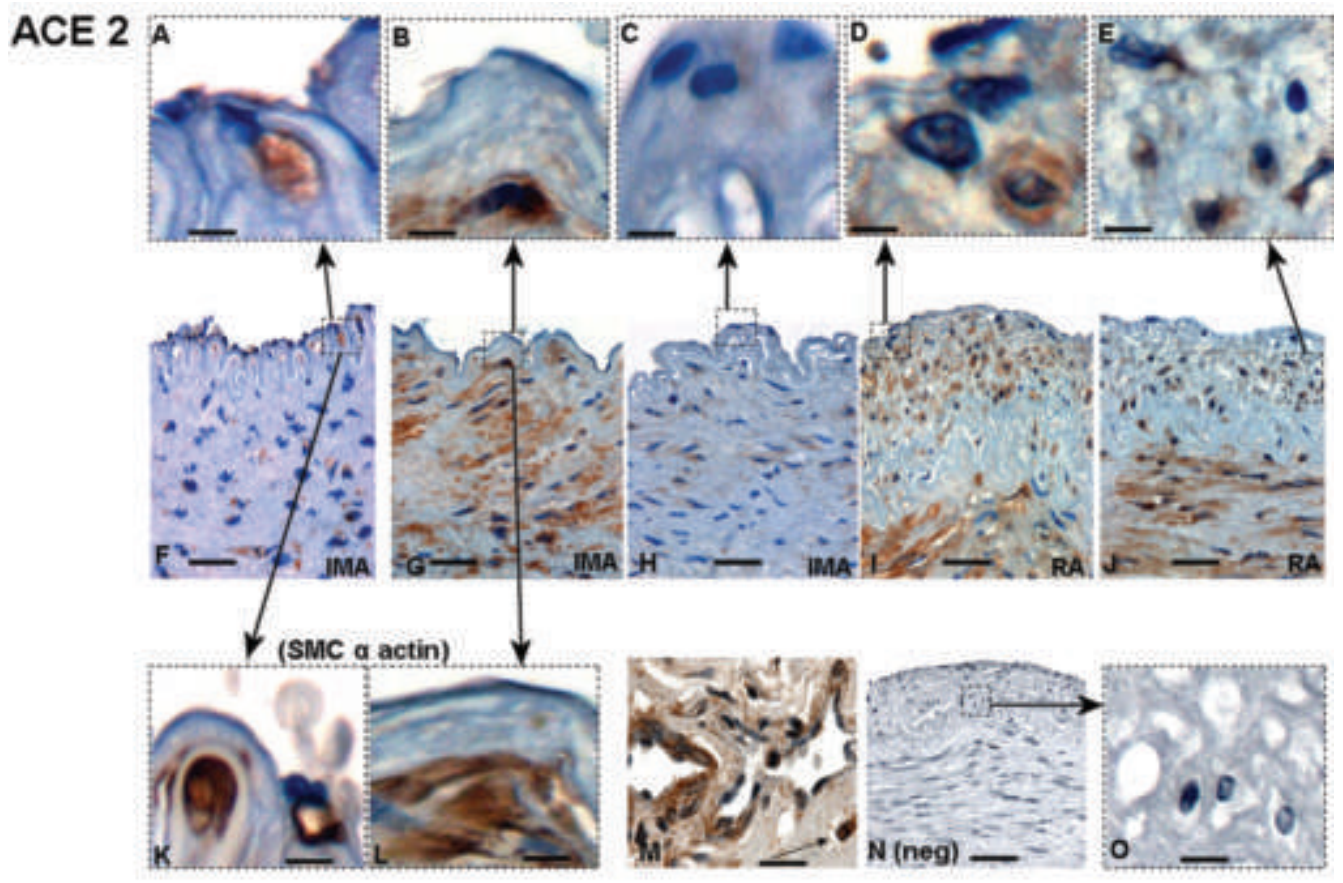

Figure 1. Photomicrographs of ACE2 immunoreactivity in IMA and RA. ACE 2 immunoreactivity was observed in the media of both normal (IMA) and diseased (RA) arteries. Specifically, single positive cells were observed just beneath the internal elastic lamina of the IMA (A,B) that also co-localised with smooth muscle cell $\alpha$ actin in serial sections $(K, L)$, however some IMA had no definitive positive cells (H, C). In the RA (I, J), ACE2 was clearly present in the cells within the intima and media, and this has been magnified (D, E), which also co-localise with smooth muscle cell $\alpha$ actin (Figure 2N, 0). ACE2 was also observed in the vaso vasorum and a single positive cell in the adventitia is clearly visible (arrow). Negative controls (monoclonal) is shown ( $\mathrm{N}$, and magnified in 0). Original magnifications are all 400x in F-J, N. Scale bars: Figures $1 \mathrm{~A}-\mathrm{E}, \mathrm{K}, \mathrm{L}=9 \mu \mathrm{m}$; Figures $1 \mathrm{~F}-\mathrm{J}=70 \mu \mathrm{m}$; Figure $1 \mathrm{~N}=35 \mu \mathrm{m}$; Figure $10=3.5 \mu \mathrm{m}$.

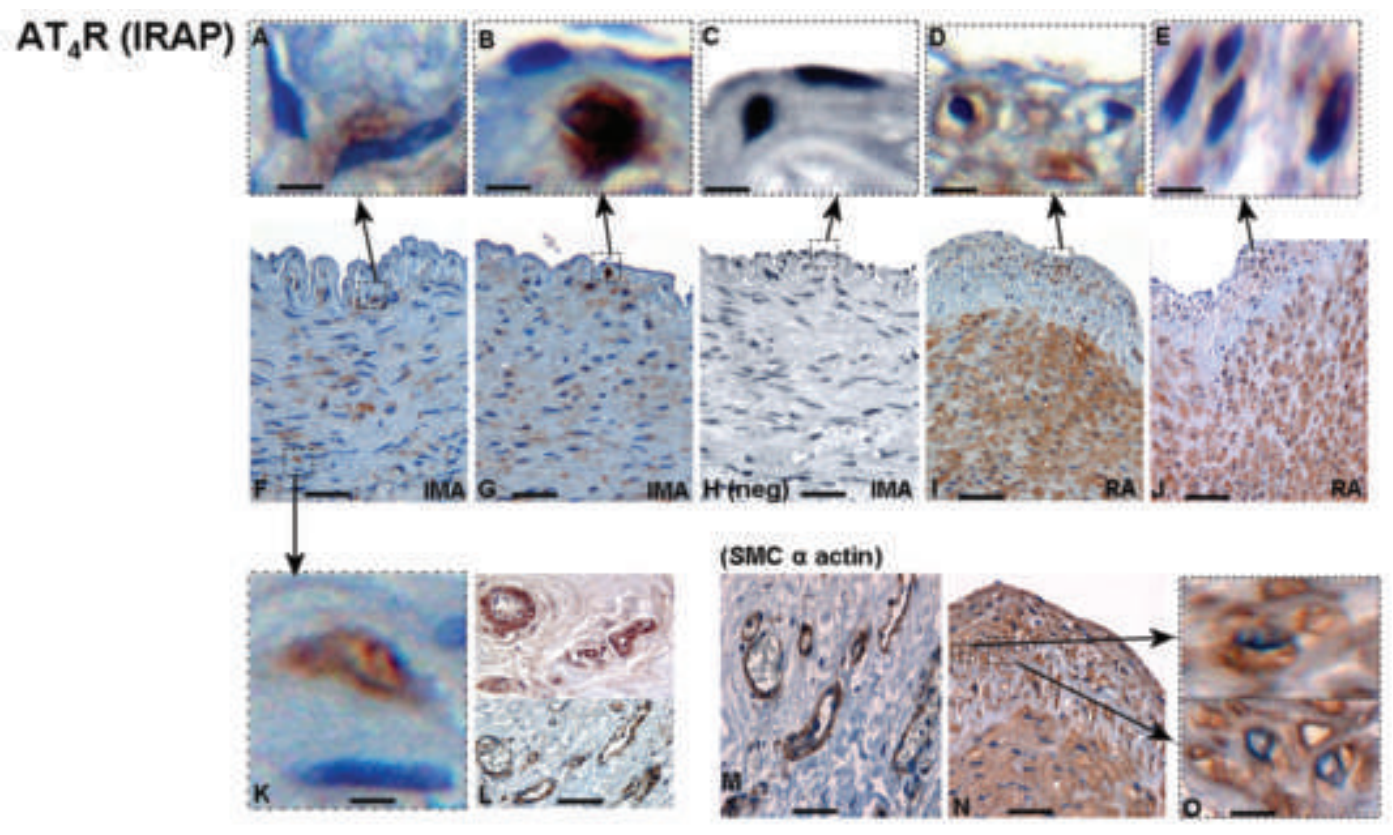

Figure 2. Photomicrographs of AT4R/IRAP immunoreactivity in IMA and RA. AT4R immunoreactivity was observed in the media of both normal (IMA) and diseased (RA) arteries. Similar to ACE2, single positive cells were observed just beneath the internal elastic lamina of the IMA ( $F, G$ and magnified in $A, B)$ and in the media $(K)$ that also co-localised with smooth muscle cell $\alpha$ actin in serial sections (Figure $1 K$, L), however some IMA had no definitive positive cells (not shown). In the RA (I, J), AT4R was clearly present in the cells within the intima and media, and this has been magnified (D, E), which also co-localise with smooth muscle cell $\alpha$ actin (Figure N, 0). AT4R was also observed in the vaso vasorum and this also correlated with smooth muscle cell $\alpha$ actin (M). Negative controls (polyclonal) is shown (H, and magnified in C). Original magnifications are all 200x in F-J, N. Scale bars: Figures 2 A-E, K = $9 \mu \mathrm{m}$; Figures 2 F-J = $140 \mu \mathrm{m}$; Figures 2 L, N = 70 $\mu \mathrm{m}$; Figure $2 \mathrm{M}=35 \mu \mathrm{m}$ Figure $20=7 \mu \mathrm{m}$. 


\section{$A C E 2$ and $A T_{4} R$ (IRAP)}
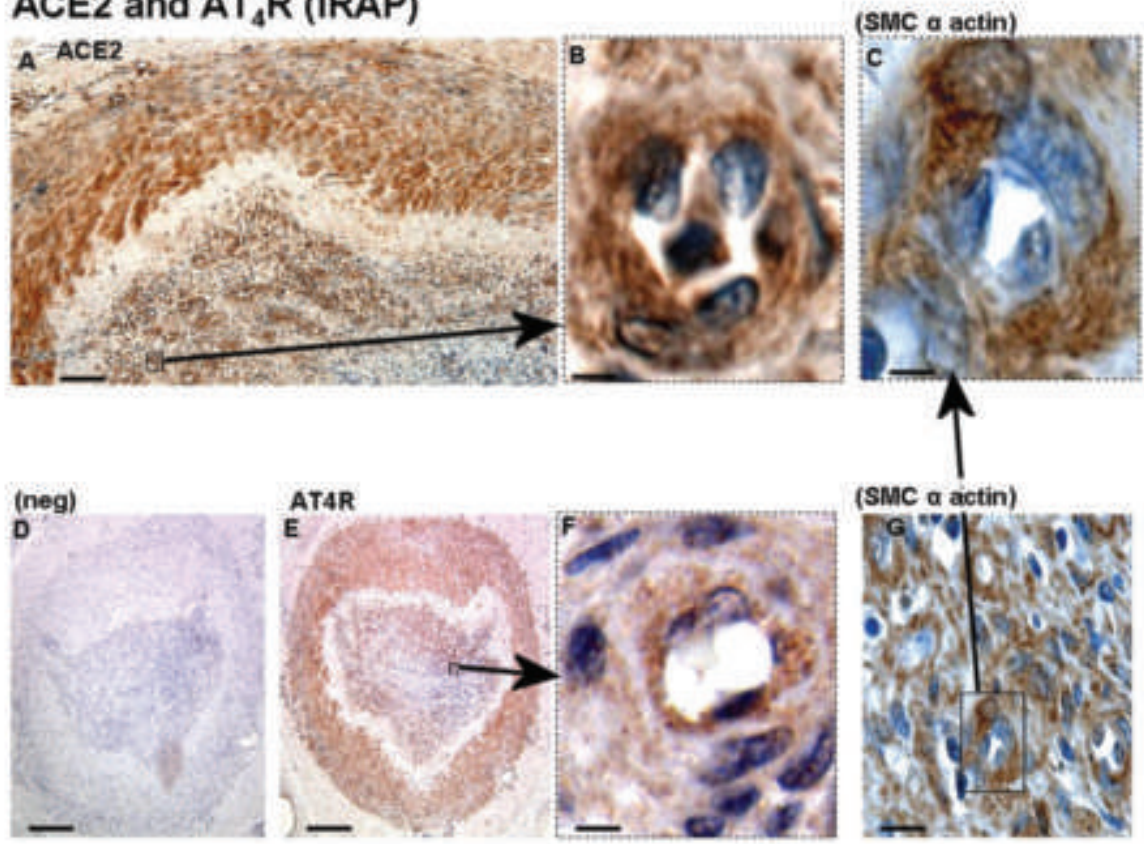

Figure 3. ACE2 (A,B) and AT4R (E,F) immunohistochemistry in the fully occluded radial artery with granulation tissue and angiogenic vessels. ACE2 (A) and AT4R (E) are clearly visible in the media of the radial artery. As well, ACE2 appears to be localised to the media of the angiogenic vessels as smooth muscle cell - actin $(C, G)$ staining shows similar localisation, but it is not clear whether endothelial ACE2 is present. On the other hand, AT4R is clearly present in the endothelium of angiogenic vessels (F) but not the media of the angiogenic vessel. Figure D shows negative control for the polyclonal antibody in the occluded radial artery. Original magnifications are 100x in $A$, 40x in D,E, and 1000x in G. Scale bars: Figure $3 \mathrm{~A}=280 \mu \mathrm{m}$; Figures $3 B, C, F=14 \mu \mathrm{m}$; Figures $3 \mathrm{D}, \mathrm{E}=660 \mu \mathrm{m} ;$ Figure $3 \mathrm{G}=35 \mu \mathrm{m}$ Figure $30=56 \mu \mathrm{m}$.

ACE2 and AT4R was clearly present in the media of the vessel, but ACE2 was present in media of the small angiogenic vessels present within the granulation tissue, and this correlated with smooth muscle cell $\alpha$ actin staining ( $C, G)$. However, AT4R did not show positive staining in the media of angiogenic vessels (F), but endothelial AT4R staining was clearly present.

\section{Discussion}

These results show that both ACE2 and AT4R are localized in a range of human blood vessels with varying intimal pathologies. Moreover, ACE2 and AT4R were not easily detectable in the endothelium of conduit vessels, but AT4R was clearly evident in the endothelium of the vaso vasorum and in angiogenic vessels.

The amount of ACE2 in tissues appears to be specific to the type of cardiovascular disease. For example, it is increased in human and rat myocardial infarction (Burrell et al. 2005) and rabbit atherosclerotic plaques (Zulli et al. 2006a), but decreased in diabetes (Tikellis et al. 2003), and hypertension (Crackower et al. 2002). However, current opinion suggests that in the vasculature, the atherogenic and mitogenic effects of Ang II are indirectly counterbalanced by ACE2. Firstly, ACE2 might have a vasoprotective role simply because it removes local Ang II from tissue. In this way, ACE2 acts as a vascular mop, whereby an increase in ACE2 to parallel an increase in ACE would help minimize the detrimental effects of Ang II. Secondly, as ACE2 produces Ang (1-7), Ang (1-7) can not only inhibit both ATIR (Roks et al. 1999) and ACE activity (Deddish et al. 1998), but also have specific effects through its novel receptor, the mas oncogene product (Mas) (Santos et al. 2003). Through Mas, Ang-(1-7) might stimulate nitric oxide synthase (NOS) and counteract the effects of Ang II. The effects of Ang-(1-7) may also involve cross-talk with the angiotensin type 2 receptor (AT2R), and the bradykinin type two receptor (BK2R) (Ferrario 1998). Taken together, this data and the data pre- 
sented in this study suggest a possible role for ACE2 and angiotensin (1-7) in cell proliferation and vasodilation in human vessels.

The primary functions related to AT4R include memory acquisition and retrieval, cerebral blood flow regulation, kidney function, angiogenesis and cardiac hypertrophy (de Gasparo et al. 2000). In larger blood vessels however, very little information exists regarding the function or localisation of AT4R. In this study, we found that endothelial AT4R (IRAP) was easily detectable in the vaso vasorum and in angiogenic vessels, but not in the endothelial layer of conduit vessels. This finding supports a previous study by Hall and colleagues, where they found that coronary microvascular endothelial cells bound radio labelled Ang IV (Hall et al. 1995). Furthermore, we observed high levels of AT4R in the media of diseased human blood vessels indicating a possible role in atherogenesis and within angiogenic vessels indicating a possible role in angiogenesis.

It is difficult to speculate at this stage the effect of patient characteristics on the expression of $A C E 2$ and AT4R in the radial and internal mammary arteries due to the sample size. The patients in this study were all receiving statin therapy with an additional hypertensive treatment such as ACE inhibition or beta adrenoceptor blockade. Further studies aimed at collecting larger samples and correlating patient characteristics with AT4R and ACE2 are ongoing.

In conclusion, we report high immunoreactivity for ACE2 and AT4R proteins in the media of diseased blood vessels as well as in angiogenic vessels, indicating a possible role for these factors in blood vessel remodelling and therefore might be involved atherogenesis.

\section{Acknowledgments}

This project has been supported in part by the Austin Hospital Medical Research Foundation and the Australian National Heart Foundation.

\section{References}

Albiston AL, McDowall SG, Matsacos D, Sim P, Clune E, Mustafa $\mathrm{T}$, et al. Evidence that the angiotensin IV $\left(\mathrm{AT}^{\prime}(4)\right)$ receptor is the enzyme insulin-regulated aminopeptidase. J Biol Chem 2001;276: 48623-6.

Benter IF, Ferrario CM, Morris M, Diz DI. Antihypertensive actions of angiotensin-(1-7) in spontaneously hypertensive rats. Am J Physiol 1995;269:H313-9.
Brosnihan KB, Li P, Ferrario CM. Angiotensin-(1-7) dilates canine coronary arteries through kinins and nitric oxide. Hypertension 1996;27:523-8.

Burrell LM, Risvanis J, Kubota E, Dean RG, MacDonald PS, Lu S, et al. Myocardial infarction increases ACE2 expression in rat and humans. Eur Heart J 2005;26:369-375; discussion 322-64.

Carey RM, Siragy HM Newly recognized components of the reninangiotensin system: potential roles in cardiovascular and renal regulation. Endocr Rev 2003;24:261-71.

Crackower MA, Sarao R, Oudit GY, Yagil C, Kozieradzki I, Scanga $S E$, et al. Angiotensin-converting enzyme 2 is an essential regulator of heart function. Nature 2002;417:822-8.

de Gasparo M, Catt KJ, Inagami T, Wright JW, Unger T. International union of pharmacology. XXIII. The angiotensin II receptors. Pharmacol Rev 2000;52:415-72.

Deddish PA, Marcic B, Jackman HL, Wang HZ, Skidgel RA, Erdos EG. N-domain-specific substrate and C-domain inhibitors of angiotensin-converting enzyme: angiotensin-(1-7) and keto-ACE. Hypertension 1998;31:912-7.

Donoghue M, Hsieh F, Baronas E, Godbout K, Gosselin M, Stagliano $\mathrm{N}$, et al. A novel angiotensin-converting enzyme-related carboxypeptidase (ACE2) converts angiotensin I to angiotensin 1-9. Circ Res 2000;87:E1-9.

Ferrario CM, Chappell MC, Tallant EA, Brosnihan KB, Diz DI. Counterregulatory actions of angiotensin-(1-7). Hypertension 1997;30:535-41.

Ferrario CM. Angiotension-(1-7) and antihypertensive mechanisms. J Nephrol 1998;11:278-3.

Freeman EJ, Chisolm GM, Ferrario CM, Tallant EA. Angiotensin-(17) inhibits vascular smooth muscle cell growth. Hypertension 1996;28:104-8.

Haberl RL, Decker PJ, Einhaupl KM. Angiotensin degradation products mediate endothelium-dependent dilation of rabbit brain arterioles. Circ Res 1991;68:1621-7.

Hall KL, Hanesworth JM, Ball AE, Felgenhauer GP, Hosick HL, Harding JW. Identification and characterization of a novel angiotensin binding site in cultured vascular smooth muscle cells that is specific for the hexapeptide (3-8) fragment of angiotensin II, angiotensin IV. Regul Pept 1993;44:225-32.

Hall KL, Venkateswaran S, Hanesworth JM, Schelling ME, Harding JW. Characterization of a functional angiotensin IV receptor on coronary microvascular endothelial cells. Regul Pept 1995; 58:107-15.

Moeller I, Clune EF, Fennessy PA, Bingley JA, Albiston $A L$, Mendelsohn FA, et al. Up regulation of AT4 receptor levels in carotid arteries following balloon injury. Regul Pept 1999;83:2530.

Nakamoto $H$, Ferrario CM, Fuller SB, Robaczewski DL, Winicov E, Dean $\mathrm{RH}$. Angiotensin-(1-7) and nitric oxide interaction in renovascular hypertension. Hypertension 1995;25:796-802.

Paizis G, Tikellis C, Cooper ME, Schembri JM, Lew RA, Smith AI, et al. Chronic liver injury in rats and humans upregulates the novel enzyme angiotensin converting enzyme 2. Gut 2005;54: 1790-6.

Patel JM, Martens JR, Li YD, Gelband CH, Raizada MK, Block ER. Angiotensin IV receptor-mediated activation of lung endothelial NOS is associated with vasorelaxation. Am J Physiol 1998;275: L1061-8.

Porsti I, Bara AT, Busse R, Hecker M. Release of nitric oxide by angiotensin-(1-7) from porcine coronary endothelium: implications for a novel angiotensin receptor. Br J Pharmacol 1994; 111:652-4.

Roks AJ, van Geel PP, Pinto YM, Buikema $H$, Henning $R H$, de Zeeuw D, et al. Angiotensin-(1-7) is a modulator of the human renin-angiotensin system. Hypertension 1999;34:296-301.

Ruengsakulrach $\mathrm{P}$, Sinclair R, Komeda M, Raman J, Gordon I, Buxton B. Comparative histopathology of radial artery versus internal thoracic artery and risk factors for development of intimal hyperplasia and atherosclerosis. Circulation 1999;100:3944.

Santos RA, Simoes e Silva AC, Maric C, Silva DM, Machado RP, de Buhr I, et al. Angiotensin-(1-7) is an endogenous ligand for the G protein-coupled receptor Mas. Proc Natl Acad Sci USA 2003; 


\section{A. Zulli et al.}

100:8258-63.

Swanson GN, Hanesworth JM, Sardinia MF, Coleman JK, Wright JW, Hall KL, et al. Discovery of a distinct binding site for angiotensin II (3-8), a putative angiotensin IV receptor. Regul Pept 1992;40:409-19.

Tikellis C, Johnston CI, Forbes JM, Burns WC, Burrell LM, Risvanis $\mathrm{J}$, et al. Characterization of renal angiotensin-converting enzyme 2 in diabetic nephropathy. Hypertension 2003;41:392-7.

Wang L, Eberhard M, Erne P. Stimulation of DNA and RNA synthesis in cultured rabbit cardiac fibroblasts by angiotensin IV. Clin Sci (Lond) 1995;88:557-62.

Wright JW, Krebs LT, Stobb JW, Harding JW. The angiotensin IV system: functional implications. Front Neuroendocrinol 1995; 16:23-52.
Zulli A, Buxton BF, Black MJ, Hare DL. CD34 Class III positive cells are present in atherosclerotic plaques of the rabbit model of atherosclerosis. Histochem Cell Biol 2005;124:517-22.

Zulli A, Burrell LM, Widdop RE, Black MJ, Buxton BF, Hare DL. Immunolocalization of $\mathrm{ACE} 2$ and $\mathrm{AT} 2$ receptors in rabbit atherosclerotic plaques. J Histochem Cytochem 2006a;54:147-50.

Zulli A, Buxton BF, Black MJ, Ming Z, Cameron A, Hare DL. The immunoquantification of caveolin-1 and eNOS in human and rabbit diseased blood vessels. J Histochem Cytochem 2006b;54:151-9.

Zulli A, Buxton BF, Black MJ, Hare DL. Embryonic stem cells markers are present within rabbit atherosclerotic plaques. Histol Histopathol 20077 in press. 